\title{
Does support for smoke-free outdoor spaces increase after implementation?: A case study of a Dutch research center's smoke-free campus transition
}

\author{
Jeroen Bommelé1, Sigrid Troelstra', Bethany Hipple Walters',2, Marc Willemsen ${ }^{1,3}$
}

\begin{abstract}
INTRODUCTION Policymakers may sometimes be reluctant to develop policies for smoke-free outdoor spaces due to concerns about public reaction. In this study, we investigated the support for a smoke-free campus before and after the campus of a Dutch research institute became smoke-free.

METHODS We conducted two surveys among employees to measure the level of support for a smoke-free campus. The first survey $(n=129)$ was conducted 3 months before and the second 13 months after the implementation of a smokefree campus policy $(\mathrm{n}=134)$.

RESULTS More employees supported the smoke-free campus after $(82.1 \%)$ than before $(64.3 \%)$ implementation $(\mathrm{OR}=2.55 ; 95 \%$ CI: $1.39-4.70 ; \mathrm{p}=0.003)$. In addition, more employees (75.4\%) employees believed it is important to have a smoke-free campus than was the situation before $(56.6 \%)$ the implementation $(\mathrm{OR}=2.28$; 95\% CI: $1.31-3.97 ; \mathrm{p}=0.004)$.

concLusions This case study adds to the knowledge that support for a smokefree campus increases after implementation of a smoke-free policy. This may encourage other organizations or local governments to create policies for smokefree outdoor spaces.
\end{abstract}

\section{AFFILIATION \\ 1 Trimbos Institute, The Netherlands Expertise Centre for Tobacco Control, Utrecht, the Netherlands \\ 2 Massachusetts General Hospital, Boston, United States \\ 3 Department of Health Promotion, University of Maastricht, \\ Maastricht, the Netherlands \\ CORRESPONDENCE TO \\ Jeroen Bommelé. Trimbos Institute, The Netherlands Expertise Centre for Tobacco Control, PO Box 725, 3500 AS, Utrecht, the Netherlands. E-mail: jbommele@trimbos.nl}

\section{KEYWORDS}

Smoke-free outdoor spaces, implementation, public support, smoking

Received: 15 September 2020

Revised: 16 October 2020

Accepted: 30 October 2020

\section{INTRODUCTION}

Employees who smoke cigarettes have increased risk of sickness and take more days sick leave from work ${ }^{1}$; employee smoking may also incur significant costs for their employers ${ }^{2}$. Smoking employees are more likely to demonstrate productivity loss than their nonsmoking co-workers ${ }^{3-5}$. Comprehensive workplace tobacco policies, including policies regarding a smoke-free campus and buildings, can make it easier for employees to reduce the amount of cigarettes they smoke ${ }^{6,7}$. Such policies may help change the smoking culture at a workplace and to reduce the number of smoking-related cues on the premises. Smokers may also have to leave the premises to smoke, thereby making it harder to smoke at work. Comprehensive workplace tobacco policies may therefore help lower smoking rates at workplaces ${ }^{8}$. Such policies would not only reduce costs, but would also help employers contribute to a future smoke-free society.

In the past decades, several national smoke-free policies have been implemented in the Netherlands ${ }^{9}$. From 1990, smoking was prohibited in public buildings. From 2004, all workers (excluding hospitality industry workers) were entitled to a smoke-free workplace and public transport became smoke-free. In 2008, a partial smoking ban in the 
hospitality industry was implemented, which was expanded to a full smoking ban in 2014 .

Inspired by the Dutch Movement Towards a Smoke-free Generation ${ }^{10}$, a growing number of public and private outdoor spaces are becoming smoke-free in the Netherlands ${ }^{11}$. The Movement Towards a Smoke-free Generation was initiated in 2017 by the Dutch Alliance for a Smoke-free Society, a partnership of Lung Foundation Netherlands, the Dutch Heart Foundation, and the Dutch Cancer Society. Its aim is to create a society in which all children born after 2017 are able to grow up smokefree, and without exposure to tobacco smoke. As a result, a number of settings in which children play and interact have become or are becoming smokefree, including petting zoos and child day care facilities (by 2020), school grounds (by August 2020), playgrounds (by 2025), and sports grounds (by 2025). In addition, a growing number of hospitals, universities, and private businesses have begun making their campus smoke-free as well ${ }^{12}$.

Recent research has shown that support for smoke-free policies is on the rise in recent years ${ }^{13-15}$, with support increasing after the implementation of such policies ${ }^{16-18}$. A 2016 systematic review of 89 US and Canadian studies showed particularly high levels of support for smoke-free school grounds ${ }^{14}$. A 2015 systematic review on the support for smokefree college and university campuses in the US and the UK reported broad support for a smoke-free campus ${ }^{19}$. A study of college students found an increase of student support from $57.5 \%$ to $62.5 \%$ two years after implementation ${ }^{20}$. A similar study among university students reported an increase of average student support from 4.57 up to 5.77 , on a 7 -point scale, after three years ${ }^{21}$.

While many studies suggest that support for smoke-free school grounds and campuses increases after implementation ${ }^{14}$, only a limited number of studies investigated changes in support for smokefree non-educational campuses, such as workplaces, office premises and industrial areas. One study that measured this explicitly was a US study on a smokefree worksite policy at a behavioral health institute ${ }^{6}$. After adopting a comprehensive smoke-free campus policy that prohibited smoking on all indoor and outdoor spaces, support for the policy among employees increased from $60.6 \%$ to $80.3 \%$ one year after implementation, according to that US study.

In this study, we investigated the change in support for a smoke-free campus among employees before and after implementing a smoke-free campus policy at a healthcare research institute in the Netherlands. The smoke-free policy included a ban on using electronic cigarettes and hookahs.

\section{METHODS}

\section{Survey design and sampling}

We conducted two surveys among employees to measure the level of support for a smoke-free campus. The campus became smoke-free in January 2019. The first survey was conducted 3 months before (September 2018) and the second one 13 months after (February 2020) implementation of the smoke-free campus policy. The first survey was deliberately conducted well before implementation to allow the institute to use any suggestions made by respondents through the survey for improving the policy. To increase survey uptake, the second survey was conducted in February, thereby avoiding the December/January holiday season. Both surveys included questions about support for the smokefree campus, as well as demographic questions. Both surveys took about three minutes to complete. In both surveys, an invitation link was sent to all employees via email and through the intranet. Employees knew about the invitation before it was sent, as this study was announced in meetings and through the intranet in the weeks before each survey wave. Due to the strict privacy regulations on handling employee data, employees were only allowed to fill in the surveys anonymously. As we have no data on who filled in both questionnaires, it is not possible to conduct longitudinal analyses.

\section{Study location}

The Trimbos Institute ${ }^{22}$ is a research institute in the Netherlands that conducts research on substance use and mental health including dissemination of information about prevention, treatment, and policy. It develops and conducts mental health and substance abuse prevention, treatment and management programs in the Netherlands and abroad. Founded in 1996 by the merging of two existing research institutes, the Trimbos Institute employs over 200 scientists, health educators and implementation 
specialists, of which about 25 work in the field of tobacco control.

The $7000 \mathrm{~m}^{2}$ campus is situated at the edge of a residential area in Utrecht, the fourth largest city in the Netherlands (with a population of 353000 ). The campus borders terraced houses, a playground, a canal, and railway tracks. The campus contains one two-story building of $300 \mathrm{~m}^{2}$ and two three-story buildings of $570 \mathrm{~m}^{2}$ and $950 \mathrm{~m}^{2}$. Buildings on the campus house both the Trimbos Institute and six smaller organizations in the field of health sciences ('tenant organizations'). Until the new policy came into effect, there was a designated smoking area at the back side of the campus (indicated in red in Figure 1).

\section{Creating a smoke-free campus}

Although all indoor worksite smoking had been banned by law at the institute since 2004 , smoking was still allowed at all outside premises in 2018. All outdoor areas at the Trimbos campus became smokefree on 1 January 2019.

Nine months before the campus became smoke-free, a committee was set up to coordinate and implement the new policy. This committee consisted of an expert in tobacco control research (MW), a representative of the employee's council, a communication expert, the head of the human resources department, the head of technical services, and a tobacco control researcher $(\mathrm{JB})$. This committee met with the employee's council, representatives of the tenant organizations, and the board of directors, to discuss how to make the campus smoke-free. Four months before the campus became smoke-free, the new policy was communicated to all employees via email, intranet posts, employee meetings, and through the survey. Smoking employees who wanted to quit smoking were offered compensation for costs related to smoking cessation. At the time of implementation, smoking cessation support was only partly covered by the universal health insurance scheme in the Netherlands.

On 1 January 2019, the campus became completely smoke-free. That day, the designated smoking area at the back side of the campus was closed and smoking at the campus grounds became prohibited (including using electronic cigarettes and hookahs). The committee placed signs at each entrance, near the former smoking area, and near the bicycle parking shed for employees who bike to work, as is common in the Netherlands. To further communicate the policy to employees, the committee provided flyers in the reception area and in all conference rooms. To inform visitors, they included a reference to the new policy in the email signatures

Figure 1. Satellite image of the research campus. Visitors enter via the main entrance on the left side of the figure, indicated with a blue dot. The previous designated smoking area was located on the back side, indicated with a red dot. Satellite image downloaded from Google Maps

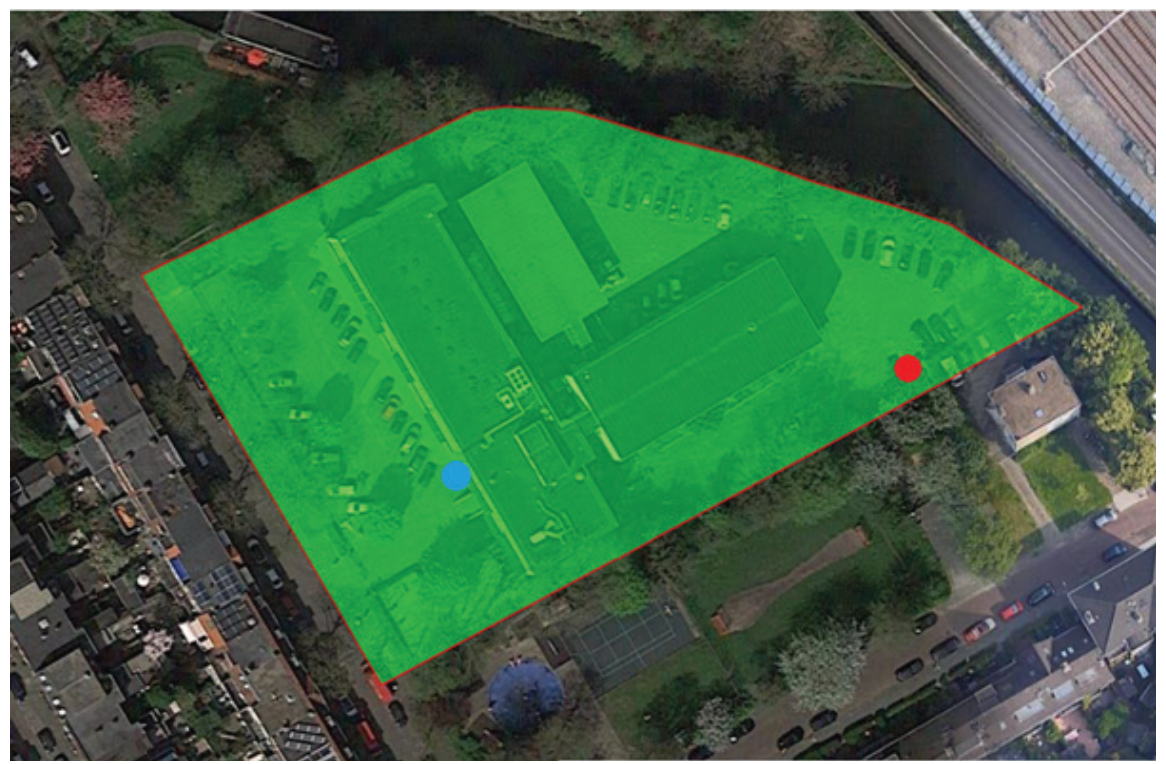


of all employees and a reference to the smoke-free policy in all job advertisements. The city councilor of Utrecht formally re-opened the campus and this event was broadly communicated through the institute's website and social media channels.

\section{Participants}

Participants were employees of the Trimbos Institute. Both employees and interns were included, and we had no inclusion or exclusion criteria. Background characteristics are presented in Table 1. The Central Committee on Research Involving Human Subjects in the Netherlands requires no ethical approval for this non-medical survey research. The study was therefore reviewed and approved by the internal Trimbos Ethics Committee (3050105).

\section{Questionnaire}

The questionnaire was developed by the project committee and the Trimbos communications department.

\section{Support for a smoke-free campus}

Participants responded to the statement: 'I support that the campus will become/has become smoke-free'. Response options were: 'agree', 'neutral', and 'disagree'.

\section{Perceived importance of smoke-free campus}

Participants responded to the statement: 'I believe it is important that the campus will become/has become smoke-free'. Response options were: 'agree', 'neutral', and 'disagree'.

\section{Analyses}

We used SPSS 25 for all analyses. We used a logistic regression to identify predictors of support for a smoke-free campus and perceived importance of having a smoke-free campus. We coded the independent variables as 1 (agree) and 0 (neutral or disagree). The factors included in our model were: time of survey, smoking status, sex, and age. We did not include any additional confounding factors.

\section{RESULTS}

Table 1 presents background statistics. We found no significant differences on any of the background variables between surveys. While 129 of 248 employees invited (52.0\%) filled in the first survey,
134 of 223 employees $(60.1 \%)$ filled in the second survey.

\section{Support for a smoke-free campus}

Support for the smoke-free campus increased significantly from $64.3 \%$ before implementation to $82.1 \%$ thirteen months after implementing smokefree campus policy at the Trimbos Institute $(\mathrm{OR}=2.55$; 95\% CI: 1.39-4.70; $\mathrm{p}=0.003$ ) (Table 2). Smokers and employees aged $>55$ years were less likely to support a smoke-free campus. Support went from $33.3 \%$ to $55.6 \%$ among the smokers ( $\mathrm{n}=12$ before; $\mathrm{n}=9$ after), from $61.7 \%$ to $79.4 \%$ among the former smokers ( $\mathrm{n}=60$ before; $\mathrm{n}=63$ after), and from $73.7 \%$ to $88.7 \%$ among the never smokers ( $n=57$ before; $n=62$ after).

\section{Perceived importance of a smoke-free campus}

The percentage of employees who believed it is important to have a smoke-free campus significantly increased from $56.6 \%$ before implementation to $75.4 \%$ thirteen months after implementation $(\mathrm{OR}=2.28$; 95\% CI: 1.31-3.97; p=0.004) (Table 3). Smokers were less likely to believe that a smoke-free campus is important. Perceived importance went from $25.0 \%$ to $44.4 \%$ among the smokers, from $53.3 \%$ to $69.8 \%$ among the former smokers, and from $66.7 \%$ to $85.5 \%$ among the never smokers.

Table 1. Sample characteristics before and after implementation of a smoke-free campus

\begin{tabular}{lrrrrr} 
& \multicolumn{2}{c}{ Before } & \multicolumn{3}{c}{ After } \\
& implementation & implementation & \\
& $\%$ & $n$ & $\%$ & $n$ & $p$ \\
Total & - & 129 & - & 134 & \\
Smoking status & & & & & \\
Never smoker & 44.2 & 57 & 46.3 & 62 & 0.735 \\
Former smoker & 46.5 & 60 & 47.0 & 63 & \\
Smoker & 9.3 & 12 & 6.7 & 9 & \\
Sex & & & & & \\
Male & 30.7 & 39 & 25.2 & 33 & 0.323 \\
Female & 69.3 & 88 & 74.8 & 98 & \\
Age (years) & & & & & \\
$<26$ & 9.4 & 12 & 9.8 & 13 & 0.666 \\
$26-35$ & 28.1 & 36 & 34.8 & 46 & \\
$36-45$ & 20.3 & 26 & 17.4 & 23 & \\
$46-55$ & 27.3 & 35 & 21.2 & 28 & \\
$>55$ & 14.8 & 19 & 16.7 & 22 &
\end{tabular}


Table 2. Predictors of support for a smoke-free campus among employees of the Trimbos Institute, Utrecht $(\mathrm{N}=263)$

\begin{tabular}{|c|c|c|c|c|c|c|c|}
\hline & B & SE $B$ & Wald & $p$ & OR & $95 \%$ CI & $\%$ \\
\hline Constant & 1.98 & 0.83 & 5.64 & $0.018^{*}$ & 7.26 & & \\
\hline \multicolumn{8}{|l|}{ Time of survey } \\
\hline Before & - & & & & & & 64.3 \\
\hline After & 0.94 & 0.31 & 9.12 & $0.003^{*}$ & 2.55 & $1.39-4.70$ & 82.1 \\
\hline \multicolumn{8}{|l|}{ Smoking status } \\
\hline Never smoker & - & - & - & $0.020^{*}$ & & & 81.5 \\
\hline Former smoker & -0.50 & 0.34 & 2.17 & 0.141 & 0.61 & $0.31-1.18$ & 70.7 \\
\hline Smoker & -1.55 & 0.57 & 7.49 & $0.006^{*}$ & 0.21 & $0.07-0.64$ & 42.9 \\
\hline \multicolumn{8}{|l|}{ Sex } \\
\hline Male & - & & & & & & 62.5 \\
\hline Female & 0.52 & 0.32 & 2.59 & 0.108 & 1.68 & $0.89-3.17$ & 78.0 \\
\hline \multicolumn{8}{|l|}{ Age (years) } \\
\hline$<26$ & - & & 5.18 & 0.270 & & & 92.0 \\
\hline $26-35$ & -1.29 & 0.81 & 2.55 & 0.110 & 0.27 & $0.06-1.34$ & 76.8 \\
\hline $36-45$ & -1.22 & 0.84 & 2.10 & 0.147 & 0.30 & $0.06-1.54$ & 75.5 \\
\hline $46-55$ & -1.51 & 0.82 & 3.41 & 0.065 & 0.22 & $0.04-1.10$ & 69.8 \\
\hline$>55$ & -1.82 & 0.85 & 4.60 & $0.032^{*}$ & 0.16 & $0.03-0.85$ & 61.0 \\
\hline
\end{tabular}

${ }^{*} \mathrm{p}<0.05$. This table presents the full model. We included no additional confounding factors.

Table 3. Predictors of perceived importance of a smoke-free campus among employees of the Trimbos Institute, Utrecht ( $\mathrm{N}=263)$

\begin{tabular}{|c|c|c|c|c|c|c|c|}
\hline & $B$ & SE $B$ & Wald & $p$ & OR & $95 \% \mathrm{CI}$ & $\%$ \\
\hline Constant & 0.19 & 0.55 & 0.12 & 0.725 & 1.21 & & \\
\hline \multicolumn{8}{|l|}{ Time of survey } \\
\hline Before & - & & & & & & 56.6 \\
\hline After & 0.82 & 0.28 & 8.43 & $0.004^{*}$ & 2.28 & $1.31-3.97$ & 75.4 \\
\hline \multicolumn{8}{|l|}{ Smoking status } \\
\hline Never smoker & - & - & - & $0.001^{*}$ & & & 76.5 \\
\hline Former smoker & -0.82 & 0.31 & 6.75 & $0.009^{*}$ & 0.44 & $0.24-0.82$ & 61.8 \\
\hline Smoker & -1.79 & 0.54 & 10.85 & $0.001^{*}$ & 0.17 & $0.06-0.48$ & 33.3 \\
\hline \multicolumn{8}{|l|}{ Sex } \\
\hline Male & - & & & & & & 56.9 \\
\hline Female & 0.44 & 0.31 & 2.08 & 0.149 & 1.56 & $0.85-2.85$ & 69.9 \\
\hline \multicolumn{8}{|l|}{ Age (years) } \\
\hline$<26$ & - & & 2.68 & 0.612 & & & 64.0 \\
\hline $26-35$ & 0.45 & 0.52 & 0.74 & 0.389 & 1.57 & $0.56-4.34$ & 72.0 \\
\hline $36-45$ & 0.53 & 0.56 & 0.87 & 0.350 & 1.70 & $0.56-5.13$ & 69.4 \\
\hline $46-55$ & 0.05 & 0.53 & 0.01 & 0.923 & 1.05 & $0.37-3.00$ & 58.7 \\
\hline$>55$ & 0.59 & 0.59 & 0.98 & 0.322 & 1.80 & $0.56-5.77$ & 65.9 \\
\hline
\end{tabular}

${ }^{*} \mathrm{p}<0.05$. This table presents the full model. We included no additional confounding factors. 


\section{DISCUSSION}

This study showed that after implementing a smoke-free campus, significantly more employees supported this measure than before the measure was implemented. In addition, more employees came to believe that it is important to have a smoke-free campus. This is in line with other research that shows that support for smoke-free polices increases after implementation ${ }^{14}$.

\section{Implications for other smoke-free outdoor spaces}

In line with previous research ${ }^{6,14,19}$, we found that initial support for the smoke-free campus was high, and increased in almost all subgroups after implementation. After the policy was implemented, more employees considered a smoke-free campus important. Non-smokers and former smokers were more likely than smokers to support the smoke-free campus, which has also been found also in other studies of smoke-free campus policies ${ }^{23,24}$.

This research shows that the implementation of a smoke-free campus policy can be a complex process for those involved, especially for those who smoke. Rather than using a strictly top-down approach, it is recommended that a steering group of employees (smokers and non-smokers, managers and staff) work together to develop the policy, address concerns and misconceptions about smokefree policies, advocate for the policy among peers, provide cessation support, educate staff on the new policy, and evaluate and update the policy as needed $^{25,26}$. However, as our research shows, these efforts may not be enough to gain complete and full employee support.

In many cases, smoke-free campus policies, such as policies for school grounds, hospital sites, and recreational areas, are not mandated by law. Reasonable arguments for smoke-free spaces can limit the resistance of smokers to these policies ${ }^{27}$. Research in Spain has shown that protecting children from tobacco smoke exposure is such a reasonable and accepted rationale for smokers and non-smokers for setting smoke-free grounds and campuse ${ }^{28}$. This argument was also communicated by Trimbos Institute. The institute further communicated that the policy was strongly aligned with its mission, vision, and values, as a healthcare research institute with a strong focus on mental health and addiction and with several researchers working in the field of tobacco control. While the Trimbos Institute borders a playground, the playground is not on the campus and is not visible from all of the grounds; this may have reduced the perceived need to have smokefree grounds to protect children from tobacco smoke exposure, and consequently influence support for its smoke-free campus policy.

Although the implementation of the smokefree campus went well, none of the smoking employees accepted the offer of compensation for smoking cessation support. Despite this, the level of compliance to the new smoke-free policy has been very high from the day it was implemented. Conversations with receptionists and members of the general and technical services revealed that all smoking colleagues adhered to the new policy from the beginning. Although there were a handful of non-complying smoking guests, even those guests left the campus quickly after being reminded of the new policy. Overall, the implementation of the new policy was met with near-universal levels of compliance.

While studies have shown that many employees support smoke-free campuses, including smokers, there may remain a group of people who do not support such policies. Despite the clear benefits that smoke-free grounds have for employees and organizations, some view such policies as an infringement on the rights of smokers ${ }^{29}$, and feel that the benefits of smoke-free outdoor spaces are overstated $^{27}$. Working with stakeholders to gain support for the policies is a crucial step, but the development and implementation of smoke-free campus policies should not wait for complete support from every patient, student, resident, or employee. As our research shows, support for the policies grows after implementation.

\section{Strengths and limitations}

A strength of this study is that we measured support for a smoke-free campus both before and after implementation. This way we were able to investigate the change in support over time, which allowed us to adapt our communication strategy if necessary. A limitation is that we had response rates of $52.0 \%$ and $60.6 \%$. While this is comparable to similar studies 
on smoke-free campuses ${ }^{19}$, it might have biased the results as people who support a smoke-free campus might have been more likely to respond to the survey invitation. Furthermore, the prevalence of tobacco smoking in this study $(9.3 \%$ before implementation of the policy) was low compared to the general adult population in the Netherlands $(22.2 \%$ in $2018)^{30}$. Since support for smoke-free policies is generally higher among non-smokers, smoke-free campus policies in organizations with more smoking employees might not experience an equally high level of support. Finally, since we were unable to link pre-implementation and post-implementation survey respondents, we could not take into account staff turnover. Despite that, we did not find significant differences in demographic characteristics among the pre-implementation and post-implementation survey samples.

\section{CONCLUSIONS}

This case study suggests that support for smoke-free outdoor spaces increases greatly after implementation of a comprehensive smoking ban. This may encourage more organizations to create smoke-free outdoor spaces, despite initial objections or hesitation by workers and management.

\section{REFERENCES}

1. Troelstra SA, Coenen P, Boot CR, Harting J, Kunst AE, van der Beek AJ. Smoking and sickness absence: a systematic review and meta-analysis. Scand J Work Environ Health. 2019;46(1):5-18. doi:10.5271/sjweh.3848

2. Berman M, Crane R, Seiber E, Munur M. Estimating the cost of a smoking employee. Tob Control. 2014;23(5):428433. doi:10.1136/tobaccocontrol-2012-050888

3. Bunn WB, Stave GM, Downs KE, Alvir JMJ, Dirani R. Effect of Smoking Status on Productivity Loss. J Occup Environ Med. 2006;48(10):1099-1108. doi:10.1097/01.jom.0000243406.08419.74

4. Baker CL, Flores NM, Zou KH, Bruno M, Harrison VJ. Benefits of quitting smoking on work productivity and activity impairment in the United States, the European Union and China. Int J Clin Pract. 2017;71(1):1-10. doi:10.1111/ijcp.12900

5. Suwa K, Flores NM, Yoshikawa R, Goto R, Vietri J, Igarashi A. Examining the association of smoking with work productivity and associated costs in Japan. J Med Econ. 2017;20(9):938944. doi:10.1080/13696998.2017.1352507

6. Seidel SE, Metzger K, Guerra A, et al. Effects of a tobaccofreework site policy on employee tobacco attitudes and behaviors, Travis County, Texas, 2010-2012. Preventing
Chronic Disease. 2017;14(12):1-9. doi:10.5888/pcd14.170059

7. Bauer JE, Hyland A, Li Q, Steger C, Cummings KM. A longitudinal assessment of the impact of smoke-free worksite policies on tobacco use. Am J Public Health. 2005;95(6):1024-1029. doi:10.2105/AJPH.2004.048678

8. Fichtenberg CM. Effect of smoke-free workplaces on smoking behaviour: systematic review. BMJ. 2002;325(7357):188. doi:10.1136/bmj.325.7357.188

9. Willemsen MC. Tobacco Control Policy in the Netherlands. Cham, Switzerland: Springer International Publishing; 2018. doi:10.1007/978-3-319-72368-6

10. Heijndijk S. Towards a Smokefree Generation in the Netherlands: From campaign to social movement to an ambition embraced by the government. Tob Prev Cessation. 2018;4(Supplement):54-67. doi:10.18332/tpc/90370

11. Bommelé J, Hipple Walters B, Willemsen M. Local tobacco control policies in the Netherlands. Utrecht, the Netherlands; 2020. https://www.trimbos.nl/aanbod/ webwinkel/product/af1751-local-tobacco-controlpolicies-in-the-netherlands. Accessed October 8, 2020.

12. Dutch Ministry of Health Welfare and Sport. The National Prevention Agreement: A healthier Netherlands. The Netherlands: Government of Netherlands; 2019.

13. Thomson G, Wilson N, Edwards R. At the frontier of tobacco control: A brief review of public attitudes toward smoke-free outdoor places. Nicotine Tob Res. 2009;11(6):584-590. doi:10.1093/ntr/ntp046

14. Thomson G, Wilson N, Collins D, Edwards R. Attitudes to smoke-free outdoor regulations in the USA and Canada: A review of 89 surveys. Tob Control. 2016;25(5):506-516. doi:10.1136/tobaccocontrol-2015-052426

15. Mark AJ, Sanders SC, Mitchell JA, Seale H, Richmond RL. Smoke-free outdoor areas: Supporting local government to introduce tobacco control policies. Aust N Z J Public Health. 2014;38(6):518-523. doi:10.1111/1753-6405.12265

16. Fong GT, Craig L V, Guignard R, et al. Evaluating the Effectiveness of France's Indoor Smoke-Free Law 1 Year and 5 Years after Implementation: Findings from the ITC France Survey. PLoS ONE. 2013;8(6):e66692. doi:10.1371/journal.pone.0066692

17. Cooper J, Borland R, Yong H-H, Hyland A. Compliance and support for bans on smoking in licensed venues in Australia: findings from the International Tobacco Control FourCountry Survey. Aust N Z J Public Health. 2010;34(4):379385. doi:10.1111/j.1753-6405.2010.00570.x

18. Hyland A, Hassan LM, Higbee C, et al. The impact of smokefree legislation in Scotland: Results from the Scottish ITC Scotland/UK longitudinal surveys. Eur J Public Health. 2009;19(2):198-205. doi:10.1093/eurpub/ckn141

19. Lupton JR, Townsend JL. A systematic review and metaanalysis of the acceptability and effectiveness of university smoke-free policies. J Am Coll Health. 2015;63(4):238247. doi:10.1080/07448481.2015.1015029

20. Seo DC, Macy JT, Torabi MR, Middlestadt SE. The effect of a smoke-free campus policy on college students' 
smoking behaviors and attitudes. Prev Med. 2011;53(45):347-352. doi:10.1016/j.ypmed.2011.07.015

21. Lechner WV, Meier E, Miller MB, Wiener JL, Fils-Aime $\mathrm{Y}$. Changes in smoking prevalence, attitudes, and beliefs over 4 years following a campus-wide anti-tobacco intervention. J Ame Coll Health. 2012;60(7):505-511. doi:10.1080/07448481.2012.681816

22. Trimbos Institute. Trimbos Institute - for mental health. https://www.trimbos.nl/english/. Published 2020. Accessed June 9, 2020.

23. Braverman MT, Hoogesteger LA, Johnson JA. Predictors of support among students, faculty and staff for a smokefree university campus. Prev Med. 2015;71:114-120. doi:10.1016/j.ypmed.2014.12.018

24. Burns S, Hart E, Jancey J, Hallett J, Crawford G, Portsmouth L. A cross sectional evaluation of a total smoking ban at a large Australian university. BMC Res Notes. 2016;9(1):1-9. doi:10.1186/s13104-016-2090-7

25. Hahn EJ, Fallin A, Darville A, Kercsmar SE, McCann M, Record RA. The Three Ts of Adopting Tobacco-free Policies on College Campuses. Nurs Clin North Am. 2012;47(1):109-117. doi:10.1016/j.cnur.2011.11.002

26. Cormac I, McNally L. How to implement a smokefree policy. Adv Psychiatr Treat. 2008;14(3):198-207. doi:10.1192/apt.bp.107.004069

27. Mlinarić M, Hoffmann L, Kunst AE, et al. Explaining Mechanisms That Influence Smoke-Free Implementation at the Local Level: A Realist Review of Smoking Bans. Nicotine Tob Res. 2018;61(2):302-320. doi:10.1093/ntr/nty206

28. Sureda X, Fernández E, Martínez-Sánchez JM, et al. Secondhand smoke in outdoor settings: Smokers' consumption, non-smokers' perceptions, and attitudes towards smoke-free legislation in Spain. BMJ Open. 2015;5(4):1-8. doi:10.1136/bmjopen-2014-007554

29. Chapman S. The smoker-free workplaces: the case against. Tob Control. 2005;14(2):144. doi:10.1136/tc.2004.010348

30. Bommelé J, Hipple Walters B, Willemsen M. Smoking in the Netherlands : Key Statistics for 2018. Utrecht, the Netherlands: Trimbos Institute; 2020. https://www. trimbos.nl/aanbod/webwinkel/product/af1698-smokingin-the-netherlands-key-statistics-for-2018. Accessed October 8, 2020.

\section{CONFLICTS OF INTEREST}

The authors have each completed and submitted an ICMJE form for disclosure of potential conflicts of interest. The authors declare that they have no competing interests, financial or otherwise, related to the current work. B. Hipple Walters, J. Bommelé and S. Troelstra report grants from Dutch Ministry of Public Health, Welfare, and Sport, during the conduct of the study.

\section{FUNDING}

This work was supported by the Dutch Ministry of Public Health, Welfare, and Sport. The sponsor had no role in the study design, data collection, interpretation of the data, writing of the report or the decision to submit a report for publication. This was the sole responsibility of the authors.

\section{AUTHORS' CONTRIBUTIONS}

All authors contributed to the design of the study and the implementation of the smoke-free campus. JB drafted the manuscript. All other authors contributed to subsequent drafts and approved the final manuscript.

PROVENANCE AND PEER REVIEW

Not commissioned; externally peer reviewed. 